\title{
Fantasmas autoritarios y precisiones conceptuales: una reflexión en torno a los aportes de Roberto Gargarella al fortalecimiento del constitucionalismo democrático en América Latina
}

\author{
Authoritarian Ghosts and Conceptual \\ Clarifications: A Reflection on \\ Roberto Gargarella's contributions to \\ Strengthening Latin American Democratic \\ Constitutionalism \\ Fantasmas autoritários e precisões \\ conceituais: reflexão sobre as \\ contribuições de Roberto Gargarella \\ para fortalecer o constitucionalismo \\ democrático na América Latina
}

David Fernando Cruz Gutiérrez* 


\section{Resumen}

El constitucionalismo y el autoritarismo se presentan como opuestos e irreconciliables. Sin embargo, la experiencia autoritaria en el mundo y en América Latina demuestra que este fenómeno se puede servir de narrativas constitucionales. Por esto, se ha desatado una expansión en la literatura jurídica preocupada por cómo afrontar esta relación. Este artículo argumenta que, pese a esta nueva literatura, la obra del profesor Roberto Gargarella aporta insumos valiosos para el fortalecimiento democrático de la región, que parten del reconocimiento de las dinámicas del constitucionalismo latinoamericano, como su carácter contramayoritario.

\section{Palabras clave}

Roberto Gargarella; autoritarismo; constitucionalismo; democracia; ciudadanía. 


\section{Abstract}

Constitutionalism and authoritarianism are deemed opposed and irreconcilable. However, the authoritarian experience in Latin America and the world shows that this phenomenon uses constitutional narratives. Concerned with how to deal with this relationship, legal literature has expanded. This article argues that, despite this new literature, Roberto Gargarella's works provide valuable inputs for the region's democratic strengthening, which stem from recognizing the dynamics of Latin American constitutionalism, such as its counter-majority nature.

\section{Keywords}

Roberto Gargarella; authoritarianism; constitutionalism; democracy; citizenship. 


\section{Resumo}

O constitucionalismo e o autoritarismo são apresentados como opostos e irreconciliáveis. Contudo, a experiência autoritária no mundo e na América Latina demonstra que esse fenômeno pode se servir de narrativas constitucionais. Por isso, uma expansão na literatura jurídica preocupada com o enfretamento dessa relação vem sendo desenvolvida. Neste artigo, argumenta-se que, apesar dessa nova literatura, a obra do professor Roberto Gargarella contribui insumos valiosos para fortalecer democraticamente a região, que partem do reconhecimento das dinâmicas do constitucionalismo latino-americano, como seu caráter contramajoritário.

\section{Palavras-chave}

Roberto Gargarella; autoritarismo; constitucionalismo; democracia; cidadania. 
Sumario: Introducción 1. Las narrativas autoritarias del constitucionalismo latinoamericano. 1.1 La expansión de nueva literatura sobre autoritarismo. 1.2. Las narrativas autoritarias latinoamericanas y su uso de la gramática constitucional. 2. Enfrentando el fantasma autoritario: aportes de Gargarella a la defensa del constitucionalismo democrático de América Latina. 2.1. El énfasis en la dimensión orgánica de la Constitución. 2.2. Pensar los retos del constitucionalismo más allá de las Cortes. 2.3 Redefinir el papel de la ciudadanía. Conclusión. Bibliografía.

\section{Introducción}

Este artículo recoge tres contribuciones del trabajo de Roberto Gargarella al constitucionalismo latinoamericano: el énfasis en la dimensión orgánica de la constitución, llevar el constitucionalismo más allá de las cortes y redefinir el papel de la ciudadanía. El interés por identificar y reconstruir estos elementos en la obra de Gargarella responde al surgimiento de una creciente literatura a nivel global y dentro del campo del derecho constitucional comparado sobre el constitucionalismo autoritario o abusivo. Los puntos que reconstruye este artículo pueden cumplir un papel protagónico en el diálogo nacional e internacional sobre este fenómeno, tanto por su potencia conceptual como por extraerse del contexto latinoamericano. En este sentido, no pretende ser una reconstrucción de toda la obra de este autor, sino identificar sus contribuciones más potentes frente a este tema.

El constitucionalismo abusivo o autoritario -a pesar de las controversias conceptuales que suscita- es un fenómeno en donde la gramática constitucional se muestra carente de los principios básicos que llenan de contenido al constitucionalismo. Las distinciones entre las constituciones que cumplen con su función y aquellas que no, en consecuencia, se vuelven más difíciles, intrincadas y paradójicas, y las amenazas a principios tan importantes como la separación de poderes no son fáciles de detectar. El autoritarismo, al adoptar una narrativa constitucional, se ha vuelto fantasmagórico. El trabajo de Gargarella, especialmente los tres elementos mencionados, ayudan a detectar en clave latinoamericana las amenazas que se presentan envueltas en el velo del lenguaje constitucional.

En la región, el fundamento ético de la democracia liberal, es decir, el imperativo de que el pueblo se gobierne a sí mismo sin que este gobierno sobrepase o se apropie del individuo, no ha logrado un robusto desarrollo. La tecnología para alcanzar este fundamento ético se remonta a la experiencia democrática fundacional de la modernidad. ${ }^{1}$ Es decir, a la Revolución americana (17651783), que estableció a la Constitución como el mecanismo para hacer viable el doble objetivo del gobierno del pueblo y el respeto del individuo. Esta ex-

1 Erik Hobsbawm, The age of revolution 1789-1848, New York, Vintage Books, 1996. 
periencia también moldeó las bases del constitucionalismo poscolonial latinoamericano, lo que generó una inclinación aristocrática que desatendía la idea de gobierno autónomo del pueblo al preferir las decisiones etiquetadas como correctas sobre las mayoritarias. ${ }^{2}$ Este viejo constitucionalismo aún mina el desarrollo democrático de la región, muy a pesar de que la Constitución Política de 1991 renovó la esperanza regional de que la Carta sirva como una herramienta para alcanzar el fundamento ético y político de la democracia liberal. ${ }^{3}$

La situación, no obstante, ha variado de manera significativa: los regímenes que se alejan ostensiblemente del imperativo democrático y constitucional ${ }^{4}$ son percibidos por Occidente como obscenidades lejanas -Corea del Norte, por ejemplo-, o como intrusos molestos -Venezuela-, mas no como un reto real a la hegemonía democrática y constitucional de la región. Debajo de esta ingenua confianza se fragua una amenaza que actúa de forma fantasmagórica. La Constitución, aquella tecnología madisoniana para mantener la democracia liberal, es utilizada con frecuencia como máscara para camuflar regímenes autoritarios. Los proyectos autoritarios de la región, tan viejos como las repúblicas de donde emergen, se presentan ahora como herederos de una gramática constitucional que se muestra carente de los principios básicos que llenan de contenido al constitucionalismo. La pregunta que surge es ¿cómo responder?

Los tres aportes de Gargarella que se presentan en este artículo son fundamentales para responder a esta pregunta y parten de recordar que la inversión en el uso del constitucionalismo no es un fenómeno nuevo en la región latinoamericana, sino que es tan viejo como las repúblicas del continente. Este recordatorio no solo permite entender las dinámicas propias del constitucionalismo de la región, sino que también supone apartarse de la expansión que está viviendo la literatura jurídica sobre la relación entre constitucionalismo y autoritarismo para proponer soluciones orientadas a enfrentar las particularidades latinoamericanas.

Para realzar los aportes de Gargarella este texto se divide en dos partes. En la primera, se presenta una reconstrucción de la literatura en torno a la relación

Idem.

3 Para profundizar entre el viejo y el nuevo constitucionalismo, véase Pedro Salazar Urguarte, “El nuevo constitucionalismo latinoamericano (una perspectiva crítica)", en Política y Derecho: derechos y garantías, México D.F., Marcial Pons, 2013.

4 Es importante destacar que la democracia y el constitucionalismo liberal son conceptos que se mezclan en la práctica constitucional contemporánea. Sin embargo, en su origen, emergieron como propuestas políticas en competencia. Durante el siglo XX el constitucionalismo liberal, en gran parte del mundo, se democratizó; al igual que muchas apuestas democráticas que se liberalizaron, dejando atrás sus formas más radicales. No obstante, la discusión subsiste aunque ya no es sobre si el constitucionalismo y la democracia pueden convivir, porque lo hacen, sino cuál es la orientación que prevalece en muchas de nuestras instituciones públicas. En el derecho constitucional en particular el tema del control constitucional de la ley suscita importantes discusiones. El trabajo de Kramer de 2004 titulado The People Themselves: Popular Constitutionalism and Judicial Review es buen ejemplo de la forma como se ha reorientado la discusión. En Colombia, un buen texto sobre esta discusión se encuentra en Vicente F. Benítez, Constitución popular, no judicial, Bogotá, Universidad de La Sabana, 2014, p. 214. 
entre el autoritarismo y el constitucionalismo para, posteriormente, mostrar cómo esta relación se articula con narrativas particulares de los proyectos políticos de América Latina. La descripción que se realiza del campo constitucional latinoamericano no parte de una reconstrucción de casos, sino de la identificación de elementos comunes. Como toda generalización pierde matices importantes, pero aun así resulta útil para el desarrollo posterior del texto, que es su principal contribución. En la segunda, en consecuencia, se presentan los aportes de Gargarella. Estos resultan mucho más potentes al estar precedidos por un desarrollo teórico sobre las relaciones entre autoritarismo y constitucionalismo en América Latina. Por último, se presentan algunos comentarios sobre el papel de la obra de Gargarella en la región.

\section{Las narrativas autoritarias del constitucionalismo latinoamericano}

\subsection{La expansión de la nueva literatura autoritaria}

La elección de Donald Trump como presidente de Estados Unidos de América generó una explosión en la literatura en torno a los peligros que enfrenta la democracia en nuestros tiempos. Trabajos como How Democracies Die de Steven Levistky y Daniel Ziblatt, How to Save a Constitutional Democracy de Tom Ginrburg y Aziz Z. Huq, y The People Vs. Democracy de Yasmcha Mounk, ilustran las preocupaciones de la academia norteamericana en torno a la fatiga democrática en la que se encuentran sus instituciones y al posible asenso del fenómeno autoritario. ${ }^{5}$ Sin embargo, previo a este suceso ya se habían publicado importantes trabajos que intentaban seguirle el paso a los fenómenos autoritarios alrededor del mundo, incluso cuando tratan de un proceso incremental de erosión democrática. De hecho, una parte importante de estos esfuerzos por sistematizar y entender la experiencia autoritaria proviene de autores norteamericanos que se habían consolidado como atentos observadores de este fenómeno -como David Landau y Tom Ginsburg-. ${ }^{6}$

A pesar de este esfuerzo académico, la noción de autoritarismo permanece difusa. Como argumenta Günter Frankenberg, el autoritarismo tiene una naturaleza camaleónica que hace difícil distinguir los márgenes del fenómeno. ${ }^{7} \mathrm{Su}$ amplitud conceptual hace que dentro de la etiqueta autoritaria se encuentren

$5 \quad$ Sobre el ascenso del autoritarismo véase Steven Levisky y Daniel Ziblatt, How Democracies Die, New York, Crown, 2018; Tom Ginsburg y Aziz Huq, How to save a constitutional democracy, Chicago, University of Chicago Press, 2018; Madeleine Albright, Fascisim: a warning, New York, Harper Collins, 2018; Yascha Mounk, The people vs. Democracy. Why our freedom is in danger and how to save it, London, Harvard University Press, 2018.

1666 Véase David Landau, "Abusive Constitutionalism”, en 47 UC Davis Law Review 189 (2013); Tom Gisnburg y Alberto Simpser, Constitutions in Athoritariam Regimes, Cambridge, Cambridge University Press, 2014.

7 Günter Frankenberg, "Authoritarian constitutionalism: Coming to terms with modernity nightmares", en Frankenberg y Alvear, eds., Authoritarian Constitutionalism, Cheltenhan UK, Eward Elgar, 2019, pp. 1-37. 
experiencias radicales y totalitarias, como el nazismo, con gobiernos con matices arbitrarios o presidencialistas, como Colombia. Es, en este sentido, "una pesadilla política y conceptual". ${ }^{8}$ La amplitud conceptual corre el riesgo de la indefinición, es decir que se aplique esta etiqueta de tal forma que cualquier fenómeno político que afecte en sentido negativo a una comunidad pueda ser considerado como producto del autoritarismo. Esto sería, como argumenta Glasious, inútil analíticamente ${ }^{9}$ y no supondría ninguna ventaja al momento de construir defensas democráticas ni constitucionales. Así, la pesadilla conceptual, cuyo origen es la dificultad para entender y clasificar el fenómeno autoritario, supone la intensificación de la pesadilla política porque impide la consolidación de defensas democráticas ante su avance $\mathrm{y}$, a su vez, convierte al autoritarismo en una etiqueta usual para desprestigiar cualquier posición en el intercambio político. En otras palabras, no se van a encender las alarmas, sino se logra precisar qué debe activarlas y menos si todo es susceptible de clasificarse como autoritarismo. En este panorama no solo es difícil plantear una definición precisa de autoritarismo, sino que tampoco resulta necesariamente útil para este estudio. Es más significativo recorrer un camino menos ambicioso que consiste en identificar cuáles son los posibles usos autoritarios de la constitución, centrándose en los autores que han mostrado las debilidades del constitucionalismo, con miras, no a derrocarlo, sino a fortalecerlo.

Habermas es un buen punto de partida. Es sus reflexiones sobre Alemania, argumentaba que la carga histórica del nazismo, de sus excesos, eliminaba el lujo de la autocomplacencia. Por el contrario, la sociedad alemana debía estar siempre alerta y volver la sospecha un imperativo social para prender alarmas tempranas ante indicios de autoritarismo. ${ }^{10}$ Esta carga, no obstante, difícilmente se puede trasladar a todas las sociedades democráticas. La política como sospecha puede incluso llegar a ser contraproducente porque mina la posibilidad de que surjan otras emociones que, de acuerdo con Nussbaum, son saludables para la política. ${ }^{11}$ La sospecha tiende a romper la compasión y la empatía, que resultan muy necesarias para el mantenimiento de la democracia. Mounk ilustra esto en una frase: "si te agradan los demás ciudadanos, no puedes estar contento si tienen problemas económicos o sufren de discriminación racial". ${ }^{12}$ Esto no implica que un grado de sospecha no sea saludable para las democracias en tanto permite que las sociedades cuestionen a sus gobiernos e interroguen a sus instituciones políticas. Pero sí, que la carga de la sospecha, al constituirse como imperativo, fracciona a la sociedad y disminuye la posibilidad de reacción ante un proyecto autoritario.

\footnotetext{
Ibid., p. 4.

Marlies Glasious, "What authoriarianism is... and is not: a practical perspective", en International Affairs 94 (3) (2018), p. 525.

10 Cfr. Jürgen Habermas, Identidades nacionales y postnacionales, Madrid, Tecnos, 1989, pp. 83-109 y 111-121.

11 Martha Nussbaum, Policial Emotions: Why love matters to justice, Cambridge MA, Harvard University Press, 2013.

12 Mounk, The people vs. Democracy, op. cit., p. 354.
} 
Históricamente, más que la sospecha, la ciudadanía ha confiado en las instituciones como guarda de sus sistemas políticos. La idea de una constitución como un documento escrito que mezcla lo político y lo jurídico, en donde se establecen las aspiraciones de una sociedad y las reglas básicas que permiten su funcionamiento, ha cumplido un papel fundamental moldeando la imaginación política de nuestra época. La constitución se ha mostrado como la herramienta para organizar el poder público y evitar que el Estado, que lo contiene, se convierta en un leviatán furioso con un apetito tal que pueda devorar de forma inclemente a los ciudadanos que debía proteger. A pesar de que esta ha sido el fundamento filosófico e ideológico del constitucionalismo-es decir, servir como una garantía ciudadana ante el ejercicio del poder-, los resultados de su aplicación varían. En la experiencia comparada es fácil encontrar constituciones impostoras o aparentes, para utilizar el término que acuñaron David S. Law y Mila Versteeg, que son aquellos documentos que a pesar de contar en apariencia con ingredientes democráticos y liberales resultan poco efectivos para materializar su contenido y enmascaran fenómenos autoritarios. ${ }^{13}$ Como si el contenido de una constitución estuviera atrincherado en la mera aspiración política y resultara carente de la fuerza necesaria para transformar la realidad $-\mathrm{o}$ al menos reflejarla-.

El fin de la historia de Fukuyama y el triunfo del capitalismo liberal impulsó la necesidad de que los regímenes autoritarios utilizaran el vestido del constitucionalismo. Hay una sospecha inmediata en la comunidad internacional que recae sobre un régimen que no cuente con una constitución que sea, al menos en apariencia, de corte liberal, aún más cuando no tiene una posición privilegiada en los mercados internacionales. Autores como Goderis y Versteeg ${ }^{14}$ consideran que esta sospecha internacional supone también un mecanismo de difusión y reproducción de constituciones genéricas, que no valoran estas reglas por su significado político para el desarrollo de un régimen democrático, es decir que no comparten sus compromisos filosóficos e ideológicos relativos al control del poder y la protección de derechos, sino que responden a la necesidad práctica de ganar aceptación y legitimidad a nivel internacional. ${ }^{15}$ En este sentido, la constitución se transforma en un mecanismo de acceso a la comunidad internacional para regímenes que no están comprometidos con los fundamentos del constitucionalismo.

La complejidad de este fenómeno ha impulsado importantes esfuerzos académicos a descubrir y afrontar el uso poco comprometido de las constituciones. David Landau, por ejemplo, acuñó en 2012 el término de constitucionalismo

13 David S. Law y Mila Versteeg, Constituciones aparentes y variaciones constitucionales entre corrientes de autoritarismo, Bogotá, Universidad Externado de Colombia, 2018.

14 Goderis Benedick y Mila Versteeg, "Transnational Constitucionalism. A conceptual framework", en Mila Versteeg, Social and political foundation of Constitutions, New York, Cambrige University Press, 2013, p. 103.

15 David Landau, de forma parecida a Goderis y Versteeg, llama a esto las cláusulas democráticas, haciendo referencia a que la comunidad internacional castiga en ciertas ocasiones el tránsito de un régimen democrático a uno autoritario. 
abusivo, para describir el uso del poder de enmienda que incluyen muchas constituciones con el objetivo de subvertir la naturaleza democrática del régimen. ${ }^{16}$ Landau argumenta que el poder de enmienda de la constitución, al introducir cambios sutiles que van desactivando aquellas instituciones necesarias para el desarrollo saludable de una democracia constitucional, termina por minar los compromisos ideológicos del constitucionalismo. La paulatina desactivación de la democracia resulta mucho más sutil e incremental que los viejos asaltos, que se materializaban a través fulminantes golpes militares. Esto, a su vez, genera una suerte de desconcierto frente a la confianza política que reposa en las constituciones, pues descubre su fragilidad.

Por su lado, Tom Ginsburg y Mark Tushnet han impulsado la idea del constitucionalismo autoritario, que ha sido de buen recibo en la academia legal transnacional, y es utilizada, reproducida y criticada por diferentes académicos a nivel mundial. ${ }^{17} \mathrm{El}$ punto de partida de Ginsburg era sobrepasar el prejuicio de que las constituciones en regímenes autoritarios son meros documentos sin ningún poder práctico y que suscitan poco interés académico. ${ }^{18}$ Superar este velo ayudó a repensar el uso de las constituciones dentro de formas de gobierno autoritarias y vislumbrar, por ejemplo, que este tipo de documentos pueden servir como una matriz de coordinación que facilita la operación del gobierno y disminuye las posibles tensiones internas. Incluso en regímenes autoritarios resulta importante saber quién hace qué. Adicionalmente, afrontar los usos autoritarios de la constitución también implica contemplar las debilidades del constitucionalismo. Tushnet, en este sentido, aporta a la compresión del fenómeno al postular que el claroscuro entre regímenes autoritarios y democracias es cada vez más difuso y resulta menos útil. Lo que hay es una suerte de mixturas democráticas y autoritarias en una escala de grises que resulta cada vez más difícil de precisar. La constitución, dentro de esta mixtura, puede soportar y justificar un ejercicio autoritario del poder del Estado. ${ }^{19}$

Ambos esfuerzos académicos, a pesar de sus diferencias, reflejan una preocupación común: una ampliación en los usos de la constitución que parece invertir las aspiraciones ideológicas del constitucionalismo. Si el constitucionalismo giraba en torno a la idea de equilibrar el doble imperativo del gobierno del pueblo con la protección del individuo, su aspiración supone, en consecuencia, establecer las reglas para el desarrollo del gobierno popular y las garantías de cada ciudadano frente a tal gobierno. El uso autoritario de la constitución la vacía de este contenido, pero mantiene sus formas. Desecha el contenido sustantivo, pero preserva sus formalidades. Duncan Kennedy ilustra este punto

\footnotetext{
16 Landau, "Abusive constitutionalism", op. cit.

17 En Colombia véase Jorge González Jácome, "From abusive constitutionalism to a multilayered understanding of constitutionalism: Lessons from Latin America", en $I \bullet C O N 15$ (2) (2017), 447-468.

18 Ginsburg y Simper utilizan la palabra meagniless para expresar que existe un prejuicio sobre el entendimiento de las constituciones en regímenes autoritarios. Una traducción aproximada es "sin importancia". Mark Tushnet, "Authoritarian Constitutionalism", en 100 Cornell L. Rev. 393 (2015).
} 
argumentado que el autoritarismo, al momento de afrontar un debate en donde se enfrenta a posiciones republicanas, empuja el lenguaje constitucional hacia la concentración de poderes, el presidencialismo o la disminución de las garantías ciudadanas. ${ }^{20}$ Sin embargo, no desecha el lenguaje constitucional, sino que se apropia de su gramática. Por ende, las constituciones y su gramática ya no solo sirven para contener y reglamentar el poder del Estado, sino que también pueden justificar arreglos constitucionales autoritarios. Como veremos, esto que parece una novedad es una práctica tradicional latinoamericana.

\subsection{Las narrativas autoritarias latinoamericanas y su uso de la gramática constitucional}

En América Latina, las constituciones han integrado gramáticas autoritarias que están sujetas a diferentes narrativas políticas necesarias para su entendimiento. La idea de una narrativa implica entender las construcciones discursivas que sustentan un uso del lenguaje constitucional. Nociones como soberanía, gobierno autónomo y poder constituyente son apropiadas por discursos políticos que las resignifican y ajustan a contextos e intereses particulares. ${ }^{21} \mathrm{En}$ este sentido, las particularidades de la región suponen un ajuste conceptual para entender la forma como opera el autoritarismo y su relación con las gramáticas constitucionales del continente. De esta manera, conviene precisar que en América las naciones se construyeron, originalmente, en torno a una constitución; su adopción apalancó la construcción de una identidad nacional en donde se consumaba la ruptura entre el nuevo país y la vieja metrópolis. El acto constitucional completaba la declaración de independencia. Sin embargo, mientras que dicha declaración suponía una ruptura, el acto constitucional consolidaba un nuevo compromiso, un horizonte común que era mucho más difícil de construir. ${ }^{22}$

De acuerdo con Gargarella, las constituciones posteriores a las guerras de independencia estaban marcadas por la tensión entre el ideal de un gobierno independiente y el ideal de la autonomía personal. Las discusiones constitucionales se planteaban en una especie de juego de suma cero entre ambos ideales, en el cual o prevalecía el gobierno independiente y se sacrificaba la autonomía individual o viceversa. ${ }^{23}$ Este antagonismo fundacional omitía la posibilidad de llegar a acuerdos ambiguos pero operativos en los textos constitucionales. ${ }^{24}$

20 Kennedy Duncan, "Authoritarian constitutionalism in liberal democracies", en Frankenberg y Alvear, eds., Authoitarian constitucionalism, Cheltenhan UK, Eward Elgar, 2019, pp. 163-164.

21 Roberto Gargarella, Los fundamentos legales de la desigualdad. El constitucionalismo en América (1776- 1860), Buenos Aires, Siglo XX, 2005, pp. 19-26.

22 La narrativa de una nueva era está presente, por ejemplo, en el discurso de Angustura que pronunció Bolívar

170 en 1919. Para profundizar, http://www.archivodellibertador.gob.ve/escritos/buscador/spip.php?article9987

23 Gargarella, Los fundamentos legales de la desigualdad, op. cit., p. 2.

24 Los interesados en este tipo de acuerdos pueden remitirse al texto de Hanna Lerner en donde explica las diferentes estrategias que han adoptado asambleas constituyentes para superar diferencias profundas en cada 
A su vez, las dificultades en la construcción del Estado y el apaciguamiento de espíritu revolucionario hicieron que triunfaran los proyectos conservadores que pugnaban por gobiernos independientes, pero de corte autoritario.

En la región, el proyecto conservador se expresó en dos escalas diferentes pero interconectadas: por un lado, a través de la imposición de un proyecto moral que aspiraba a un ideal de perfección orientada a alcanzar un molde católico, lo que comprimía la autonomía individual. Y, por el otro, un elitismo político que cercenaba la ampliación de los derechos democráticos de participación política a grandes sectores de la población, por considerarlos como atávicos e irracionales. Ambas dimensiones tuvieron efectos tangibles en la construcción de los proyectos constitucionales del continente. Surgieron constituciones confesionales que a su vez concentraban el poder en la figura del presidente y limitaban la participación política a propietarios o personas alfabetizadas. ${ }^{25}$ Así, los contornos del proyecto conservador se relacionan con una determinada gramática constitucional que punga por un modelo presidencialista con una concentración de poder. Esta raigambre autoritaria aún permanece en muchas constituciones contemporáneas de la región, incluso en aquellas que han sido etiquetadas como parte del "nuevo constitucionalismo latinoamericano" ${ }^{26}$

Por otro lado, la región ha estado históricamente sometida a una presión económica que ha menguado la capacidad de autodeterminación de las naciones que la integran. Según Eslava, particularmente en la segunda mitad del siglo XX, esta presión ha generado un molde sobre el Estado posible. ${ }^{27} \mathrm{El}$ ideal de desarrollo construido en los países del Norte Global propició una transformación en la legitimidad de los países del Sur Global orientada a establecer como criterio de evaluación de lo legítimo el crecimiento económico y la industrialización. El desarrollo, en consecuencia, se convirtió en un discurso poderoso que respondía a un esquema de incentivos construido a través de la aceptación en la comunidad internacional. Este ideal, adicionalmente, viene acompañado de un paquete de instituciones internacionales que formulan periódicamente recomendaciones para los Estados que adoptan e implementan internamente el discurso desarrollista. La paradoja es que la inclusión en la comunidad internacional constituye un imperativo, pues supone para muchos Estados del Sur Global la oportunidad de acceder a ventajosas redes de comercio transnacional, al tiempo que genera una pérdida en autonomía, pues implica supeditar las decisiones internas a las recomendaciones internacionales. Este

una de las sociedades (Hanna Lerner, Making Constitutions in Deeply Divided Societies, New York, Cambridge University Press, 2011).

25 La figura del presidente monarca, por ejemplo, muestra algunas aspiraciones de la figura del presidente en América Latina.

26 Se entiende por Nuevo Constitucionalismo Latinoamericano una serie de renovación constitucional que normalmente es originada en el proceso constituyente colombiano de 1991. Más arriba se indicaron autores que pueden dar una mirada sobre esto. 
esquema crea, en palabras de Diego López, Estados con soberanías abiertas ${ }^{28}$ que son complacientes ante la presión internacional, pero que internamente disciplinan territorios y poblaciones si esto resulta necesario para cumplir con los índices de desarrollo y crecimiento económico.

Esta presión económica también ha despertado otras narrativas autoritarias de la gramática constitucional. Estas conciben la presión internacional como un mecanismo de marginalización. La construcción de este orden internacional supone una desventaja para los países del Sur Global que deben subordinar sus propios intereses y discusiones internas para alcanzar un grado de aceptación que resulta precario. El discurso desarrollista, de acuerdo con esta visión, supone una puerta de entrada al proyecto de la modernidad. Pero sus efectos son limitados, ya que solo genera un acceso parcial a sus beneficios, lo que sitúa a estos Estados como proveedores de materias primas dentro de la dinámica económica global. En consecuencia, las aspiraciones de autogobierno y de soberanía que tienen una relación directa con la gramática constitucional, resultan atractivas para proyectos políticos que se enfrentan a este orden económico. González Jácome muestra que la teoría sobre el poder constituyente desarrollada por Carl Schmitt es particularmente atractiva para retomar un ámbito de discrecionalidad interno, pues entiende a la constitución como una decisión soberana sobre la unidad y la forma de la nación..$^{29}$ En este sentido, el despliegue de la teoría del poder constituyente, dentro de los múltiples niveles de discusión que suscita la práctica constitucional de la región, puede leerse como un mecanismo para recuperar la soberanía en contra de las presiones económicas.

La narrativa de recuperar la soberanía y luchar contra presiones económicas internacionales se evidencia, por ejemplo, en el proyecto de la Asamblea Constituyente de 1999 de Venezuela, dominada por Hugo Chávez y sus partidarios. Una justificación importante para la activación del poder constituyente fue la recuperación de la soberanía para resistir contra presiones económicas neoliberales que buscan definir los contornos regionales del Estado. ${ }^{30}$ Algo similar ocurrió con la Constitución ecuatoriana de 2008 que fue impulsaba por la figura de Rafael Correa, quien posteriormente sería presidente de esta nación. Las Asamblea Ecuatoriana sirvió como mecanismo para repensar un modelo económico que pueda hacerle frente a la "larga noche neoliberal". ${ }^{31}$ Estos proyectos difícilmente pueden calificarse como conservadores. Por el contrario, están emparentados con reivindicaciones políticas marginadas por los poderes

28 Diego López-Medina, “El nacimiento del derecho comparado moderno como espacio geográfico y como disciplina: instrucciones básicas para su comprensión y uso desde América Latina", International Law, Revista Colombiana de Derecho Internacional 26 (2015), pp. 117-159, DOI: http://dx.doi.org/10.11144/ Javeriana.il15-26.ndcm

29 Jorge González Jácome, "From abusive constitucionalism to a multilayered understanding of constitucionalism: Lesson from Latin America", en I•CON 15 (2017), pp. 447-468.

$172 \quad 30 \quad$ Jorge González Jácome, "Authoritarianism and the narrative power of constitutionalism in Venezuela", en Frankenberg y Alvear, eds., Authoritarian Constitutionalism, Cheltenhan UK, Eward Elgar, 2019, p. 137.

31 Alfredo Serrano Mancilla, “Por qué es fundamental estudiar la Constitución Económica de Ecuador?” en La Nueva Economía en la nueva constitución de Ecuador, Providence, Brown University, 2015, pp. 13-16. 
conservadores de la región. En consecuencia, sus banderas están relacionadas más con la transformación política que con la conservación de sus dinámicas. La ruptura sucede porque esta gramática del poder constituyente rechaza el modelo de elitismo político que intrínsecamente abarca el proyecto conservador. Esta disociación supone una transformación en el fundamento del poder. De esta forma, mientras que el proyecto conservador rechazaba el fundamento mayoritario y abrazaba una idea de corrección en las decisiones políticas, el proyecto transformador encarna una aspiración popular que prefiere la aprobación o el soporte mayoritario, y desecha la idea de corrección política.

A pesar de estas diferencias, el eje que une ambas narrativas autoritarias sigue siendo la aspiración de un gobierno autónomo. Este punto en común permite que Hugo Chávez rescate a Simón Bolívar como una figura que pugnaba por la independencia de la región ante poderes imperiales, ${ }^{32}$ aún a pesar de que Bolívar ha sido tradicionalmente apropiado por el proyecto conservador. ${ }^{33} \mathrm{La}$ narrativa constitucional, en este sentido, también supone una declaración de independencia y de resistencia en contra de poderes que intentan menguar la soberanía. Cumple, en consecuencia, una función evocativa de la unidad nacional que, a su vez, se presenta como autónoma e independiente. Sobre esta unidad se fundamenta la construcción de poderes autoritarios ya sea para transformar como para conservar los proyectos políticos de la región. El énfasis en el ideal del gobierno autónomo relega la preocupación por las garantías constituciones orientadas a la libertad individual. En este sentido, el uso autoritario de la gramática constitucional en la región supone un desbalance entre los ideales del constitucionalismo, que impulsa fenómenos como la concentración de poderes, la supresión de garantías individuales y el debilitamiento de los parlamentos.

\section{Enfrentando el fantasma autoritario: aportes de Gargarella a la defensa del constitucionalismo democrático de América Latina}

\subsection{El énfasis en la dimensión orgánica de la Constitución}

Las constituciones tienen una función nominadora. Ligan territorios geográficos con organizaciones políticas, construyen identidades nacionales, definen un paquete de derechos, etc. Por ende, estos documentos también construyen

\footnotetext{
32 Véase González Jácome, "Authoritarianism and the narrative power of constitutionalism in Venezuela", op. cit., p. 137.

33 También cabe precisar que Chávez no ha sido el único que ha reivindicado la figura de Bolívar como un héroe revolucionario. Guerrillas como el M-19 han utilizado su figura a través de golpes mediáticos, como el robo de una de sus espadas el 17 de enero de 1974, bajo la consigna de "la espada de bolívar vuelve a la lucha".
} 
una parte del flujo de sentido por el cual las personas nos relacionamos con el mundo. Esta función nominadora tiene un doble efecto de encanto y satisfacción. Como lo ha destacado Julieta Lemaitre, nombrar el mundo es también adueñarse de este, etiquetarlo y subordinarlo. ${ }^{34}$ Supone la paradoja del lenguaje mismo, que al momento en que se utiliza encapsula y limita el objeto sobre el que recae. Así, de la indeterminación se pasa a la certeza. Definir un Estado es similar, implica un acto de creación, el tránsito de un territorio a una comunidad política. Un paso de lo natural a lo político. Funciona casi como un encantamiento, pues es la voluntad que se expresa en el acto de creación la que posteriormente transforma el mundo -o al menos aspira a esto-. Se pasa de la naturaleza a la República.

El encantamiento supone creer que el cambio es inmediato. Que lo que se expresa en una Constitución, por su efecto nominador, altera la realidad. Cuando una cosa es el deseo de cambiar algo y otra la capacidad para hacerlo. Esta distinción entre el deseo y capacidad es fundamental para la experiencia constitucional de la región, pues implica la evidente disociación entre los postulados constitucionales y la realidad de quienes habitan el conteniente. A modo de ilustración, el artículo 22 de la Constitución Política de Colombia de 1991 establece la paz como un derecho y un deber de obligatorio cumplimiento. Esto contrasta con el lamentable hecho de que durante los primeros diez años de dicha Constitución el conflicto armado interno se recrudeció hasta alcanzar una escala que aún no se termina de vislumbrar. ${ }^{35}$ Las distancias entre el deseo y la capacidad se acrecentaron y no se saldan con la mera aspiración. Esto sucede, en escalas distintas, en varios de los proyectos constitucionales de la región, particularmente frente a los deseos democráticos de muchas constituciones que contrastan con las prácticas autoritarias de sus gobiernos. Cartas Políticas que abanderan la dignidad humana contrastan con cárceles hacinadas que se convierten en mecanismos de tortura sistemática para quienes se encuentran recluidos -muchas de estas personas sin estar ni siquiera condenadas- ${ }^{36}$

El efecto de encantamiento también se relaciona con una cierta sensación de satisfacción. Nombrar el mundo, como deseo, genera una satisfacción. Una ilusión de propiedad y de alcanzar una meta. Las constituciones, en este sentido, satisfacen deseos políticos de quienes participan en su construcción y de los miembros de la sociedad que se ven representadas en estas. La parte

34 Julieta Lemaitre Ripoll, El derecho como conjuro: fetichismo legal, violencia y movimientos sociales, Bogotá D.C. Siglo del Hombre Editores/Universidad de los Andes, 2009, pp. 383-392.

35 Varios textos sobre el conflicto armado colombiano ilustran esta situación. Vale la pena revisar el informe del Centro Nacional de Memoria Histórica (CNMH), ;BASTA YA! Memorias de guerra y dignidad, que constituye una sistematización de las dinámicas e impactos del conflicto. También es útil el texto de Ariel Avila, Detrás de la Guerra en Colombia, Bogotá, Planeta Editores, 2019, pues supone una valiosa recopilación de datos sobre

17436 Véase Manuel Iturralde y Libardo Ariza, Los muros de la infamia. Prisiones en Colombia y en América Latina, Bogotá, Uniandes Ediciones, 2011; Roberto Gargarella, Castigar al prójimo: por una refundación democrática del derecho penal, Buenos Aires, Siglo Veintiuno Editores, 2016, pp. 24 y ss. 
dogmática de la Constitución -en los términos de Gargarella-, ${ }^{37}$ es decir, los derechos y las garantías de los ciudadanos, parece producir una mayor satisfacción que la parte orgánica, es decir, la organización y distribución del poder público. Esto se debe, en parte, a que el lenguaje de los derechos es intrínsecamente moralizante. Así, declarar que los ciudadanos tienen un derecho también supone una afirmación moral, que contrasta con una región plagada de atropellos, de violaciones de derechos humanos y de inequidad. En este sentido, el lenguaje de los derechos, al tejer aquellas redes de sentido que definen lo humano, reconociendo a qué se tiene derecho por esta condición, supone también negar las situaciones que impiden el goce de estos derechos y aspirar a transformarlas. De ahí la satisfacción.

Las amplias cartas de derechos de algunas constituciones de la región pueden explicarse por el afán social de consolidar este deseo de transformación. Por consolidar una fantasía constitucional "que aspira a definir, incluso, a producir, la realidad social, o por lo menos una realidad alternativa".$^{38}$ El enfoque en los derechos, que son el contenido de estas fantasías constitucionales, suele dejar de lado la consolidación de las condiciones para alcanzarlas. ${ }^{39}$ De esta forma, el encanto de creer que nombrar algo supone su transformación, anudado a la satisfacción de que lo que se nombra niega lo que existe, descuida algo fundamental en el acto constitucional: la distribución adecuada del poder público. En este punto, Roberto Gargarella recuerda que las condiciones para alcanzar las fantasías constitucionales no son ajenas a la misma constitución, sino que se encuentran en su "sala de máquinas". ${ }^{40}$ Es decir, en el diseño institucional que tiene el poder público. No es que las cartas de derechos sean en sí mismas un ardid de distracción frente a lo realmente importante, sino que las fantasías constitucionales precisan de un motor que les permita superar su etapa aspiracional, y el engranaje de este motor depende de cómo se distribuya el poder público. Una distribución desequilibrada transforma la fantasía en una odisea.

Dos de los grandes trabajos de Gargarella gravitan en torno a este punto. Ambas obras, que comparten un flujo de sentido y podrían considerarse como dos tomos de un mismo estudio, constituyen una crítica clave al constitucionalismo de la región: por un lado, Los fundamentos legales de la desigualdad. El constitucionalismo en América (1776-1860), que puede considerarse como el primer tomo; y por el otro, La sala de máquinas de la Constitución, dos siglos de constitucionalismo en América Latina (1810-2010) que se puede considerar como el segundo tomo.

37 Roberto Gargarella, ¿Qué es la Constitución?, en http://lalibertaddepluma.org/roberto-gargarella/, fecha de consulta: 10 de mayo de 2020.

38 Lemaitre Ripoll, El derecho como conjuro, op. cit., p. 395.

39 Una reflexión sobre el constitucionalismo aspiracional se encuentra en el siguiente texto: Mauricio García Villegas, "Constitucionalismo aspiracional: derecho, democracia y cambio social en América Latina”, en Análisis Político (75) (2012), pp. 89-110.

40 Roberto Gargarella, La sala de máquinas de la constitución. Dos siglos de constitucionalismo en América Latina (1810-2010), Buenos Aires, Katz Editores, 2014, p. 44. 
En la primera obra Gargarella reconstruye el clima político que dio lugar a las primeras constituciones de la región, identificando los diferentes proyectos que surgieron en este periodo y sus pugnas por establecer una "organización constitucional" ${ }^{\prime 1}$-es decir, la consolidación de una estructura social particular-, que se acomodaba a sus ideales políticos. De acuerdo con Gargarella, tres proyectos constitucionales tuvieron presencia en la región: el constitucionalismo radical, emparentado con ideales republicanos de autogobierno, la moral privada y la primacía de la voluntad mayoritaria; el constitucionalismo liberal, comprometido con la autonomía individual, la neutralidad del Estado ante la religión, la propiedad privada y el principio de separación de poderes; y el constitucionalismo conservador, promotor de un perfeccionamiento moral y de un elitismo político que limitaba la participación de amplios sectores de la sociedad. La relación trialéctica entre los tres proyectos definió los contornos del viejo constitucionalismo latinoamericano.

El constitucionalismo radical y el liberal, que encontraron un punto de apoyo común entre la afirmación del individuo y el rechazo a modelos dictatoriales de gobierno, sirvieron como muro de contención ante las versiones más nocivas y autoritarias del constitucionalismo conservador. Sin embargo, la relación entre el liberalismo y el radicalismo se disolvía, en la mayoría de ocasiones, una vez lograban contener los avances conservadores sin que sus puntos en común permitieran construir proyectos políticos conjuntos. ${ }^{42}$ En cambio, los lazos entre el constitucionalismo liberal y el conservador, aún con sus tensiones intrínsecas, lograron acuerdos políticos para bloquear la principal reivindicación de constitucionalismo radical que consistía en la prevalencia de las decisiones mayoritarias en el proceso político. En palabras de Gargarella:

\begin{abstract}
... los vínculos entre liberales y conservadores, sin embargo, son todavía más profundos y, por lo que vimos, resultaron más fructíferos en la práctica. Existe, por supuesto, una seria fuente de tensión entre el proyecto moral y el conservadurismo y el abstencionista o neutralista de los liberales [...] Sin embargo, la oposición entre el modelo defendido por los conservadores y el que defienden los liberales dista de ser absoluta, en términos teóricos. Las dos posturas, en efecto, rechazan el activismo político mayoritario, ven con desconfianza el recurso frecuente a la ciudadanía, y se inclinan por las soluciones institucionales que privan a ésta del derecho a tener la última palabra en el proceso decisorio. La afinidad entre ambas posturas reside, en definitiva, en un cierto elitismo político, más o menos acentuados según el caso, pero siempre significativo. ${ }^{43}$
\end{abstract}

La fortaleza del acuerdo liberal-conservador radicaba en la defensa de la propiedad privada. Cuando esta última se encontraba en peligro, ambos proyectos cerraban filas para mitigar cualquier efecto indeseado en su contra. Las otras disputas se mostraban superables. A su vez, estas alianzas suponían una 
distribución del orden constitucional que matizaba ambos proyectos, lo que generaba una textura liberal-conservadora en el constitucionalismo fundacional de la región. ${ }^{44}$ Sin embargo, la distribución del orden constitucional daba prevalencia a los liberales en la parte dogmática de la constitución -salvo en temas religiosos- y a los conservadores en la parte orgánica de la misma. De esta forma, las convenciones entre ambos proyectos generaron pactos constitucionales de algún grado de inspiración liberal, pero que tenían arreglos constitucionales autoritarios. Bajo esta fórmula, el modelo presidencialista latinoamericano, en el cual el poder ejecutivo actúa sin un control por parte de las demás ramas del poder público, se impuso en la región con un claro carácter contramayoritario. Las tensiones producto de esta distribución fomentarían la inestabilidad de estos pactos, y allanaron el camino para los cismas liberalesconservadores que convulsionaron a varios países durante los siglos XIX y XX.

La enseñanza de este estudio es que la declaración de un derecho no basta para su protección. Menos aún, cuando su ejercicio implica la posibilidad de disputar el poder institucional. En estos casos, su efectividad está ligada a que el que diseño institucional lo fomente y lo proteja; pues en caso contrario corre el riesgo de caer en letra muerta. Bajo esta idea, el modelo presidencialista que reflejaba el constitucionalismo conservador tiene el potencial de desarticular aquellas garantías de participación democráticas que permiten disputar el poder institucional. En este sentido, este modelo no solo es el reflejo de un elitismo político, sino que supone la posibilidad de su fortalecimiento. Esta lección, adicionalmente, permite articular la primera obra con la segunda, y posiciona al principio de separación de poderes y al sistema de frenos y contrapesos en un lugar central dentro del análisis del constitucionalismo de la región, pero expandiendo su estudio desde la etapa fundacional hasta los albores del siglo XXI. Así, esta idea se presenta de forma temprana en la lectura de La sala de máquinas de la Constitución, donde se establece lo siguiente:

El sistema de frenos y contrapesos aparece entonces, originariamente, como un excelente ejemplo del compromiso liberal con la libertad individual, y de su certeza de que ninguna de las concepciones rivales sería capaz de evitar las peores amenazas que se cernían sobre la misma. En efecto, el sistema de "frenos y contrapesos" no vino a significar otra cosa que un decidido esfuerzo por organizar al sistema institucional contra los riesgos que las propuestas alternativas dejaban abiertos. Así, y contra la vocación conservadora por concentrar la autoridad política en una persona (si no de transferirle directamente poderes extraordinarios), los liberales prohibieron la delegación de facultades extraordinarias, auspiciaron la descentralización del poder, y limitaron estrictamente los poderes normativos del presidente. A la vez, y contra la disposición republicana a convertir a la Legislatura en un órgano soberano, todopoderoso, prácticamente ilimitado. ${ }^{45}$

$44 \quad$ Esta textura liberal-conservadora también se desarrolla en La sala de máquinas de la constitución, particularmente en el capítulo 2, titulado “El 'constitucionalismo de fusión': el pacto liberal conservador en la mitad del siglo XIX". 
El extenso periodo de la segunda obra -que abarca dos siglos de constitucionalismo latinoamericano- presenta un esfuerzo adicional por intentar distinguir si las constituciones contemporáneas -o sus cambios-, han supuesto una ruptura con sus predecesoras. Dicho en otras palabras, Gargarella cuestiona si la renovación constitucional que ha sufrido la región ha ayudado a la transformación de los viejos regímenes y ampliado el ideal democrático de autogobierno colectivo. La raíz de este cuestionamiento se encuentra en el renacimiento constitucional de la región, que fue etiquetado como "nuevo constitucionalismo latinoamericano", presuponiendo una ruptura con las prácticas constitucionales del pasado. La etiqueta de novedad, de acuerdo con Gargarella, tiene que ver con el hecho de nombrar lo que estuvo ausente en los proyectos constitucionales anteriores y atender en consecuencia a la cuestión social. De esta forma, la renovación tiene que ver con el compromiso constitucional con derechos sociales, económicos y culturales que se habían postergado por la textura liberal-conservadora que había dominado la región. Este cambio, aunque valioso, a los ojos de Gargarella no implica una ruptura con el viejo constitucionalismo, porque persisten las estructuras de poder de la vieja usanza. Se materializó el deseo, mas no se consolidó un motor para el cambio.

Karl Loewenstein decía que el constitucionalismo es un vestido muy lindo que le queda grande a América Latina. ${ }^{46}$ Así, cuando los Estados de la región lo visten, a pesar de estar bien adornados, demuestran sus falencias. Lo que ha hecho el nuevo constitucionalismo es mejorar la calidad del vestido. Las cartas de derechos y la inclusión de quienes tradicionalmente han sido excluidos en la región -indígenas y afros, principalmente- son una novedad relevante $\mathrm{y}$ valiosa dentro del constitucionalismo latinoamericano, pero es insuficiente para que genere un rompimiento con el viejo constitucionalismo, porque aún persiste un arreglo constitucional autoritario. Y este continuum es tan relevante que impide que las nuevas fantasías constitucionales transformen la realidad. En este sentido, no hay rompimiento sino una mera enunciación. Hay solo el deseo de cambio. Lo que podría constituirse como un motor de transformación es la reformulación del sistema de frenos y contrapesos, ya no para limitar los embaces conservadores y radicales, sino para maximizar el ideal de gobierno autónomo y colectivo. De pronto así, el vestido del constitucionalismo ajuste.

Por todo esto, el énfasis en la parte orgánica de la constitución también supone una alerta. Por un lado, dejar de engordar el deseo implica dejar de ampliar las cartas de derechos para centrar el esfuerzo en la articulación de las ramas del poder público. Pues esta articulación hace que el vestido ajuste. Así, la contribución de Gargarella se vuelve potente: la forma como se diseña el sistema de poder institucional implica también la posibilidad de que las cartas de derechos se vuelvan realidad. Esto, por otro lado, también supone hacerles frente a las

46 Cfr. K. Loewenstein, “La 'Presidencia' por fuera de los Estados Unidos”, en Boletin del Instituto de Derecho Comparado de México II (5), 1949, pp. 27-28. 
narrativas latinoamericanas del constitucionalismo autoritario. El ideal de un gobierno autónomo va de la mano con su talante democrático y colectivo. La disociación entre ambos es la alerta para revisar el funcionamiento la sala de máquinas de la constitución. De esta forma, se invierte la odisea: ya no es de las cartas de derechos por materializarse, sino del autoritarismo por volver.

\subsection{Pensar los retos del constitucionalismo más allá de las cortes}

Pocas innovaciones jurídicas han generado tanto entusiasmo como el modelo concentrado del control constitucional de la ley. Si bien el control constitucional se remonta a 1803 en el famoso caso de Marbury vs. Madison en donde por primera vez la Corte Suprema de Justicia de Estados Unidos inaplicó una ley por considerarla contraria a la Constitución, es la Constitución Federal de Austria de 1920 la que incluye por primera vez un tribunal dedicado a la justicia constitucional. ${ }^{47}$ La materialización de una de las ideas más importantes de la obra de Hans Kelsen -a la cual él contribuyó muy activamente ${ }^{48}$-, es decir que un tribunal defendiera la esencia de la ley fundamental o la Constitución ante los desarrollos del legislador, supuso la semilla de un cambio con efectos mundiales. De esta forma, las constituciones posteriores a la Segunda Guerra Mundial han incluido con regularidad una Corte dedicada al control constitucional de la ley, lo que ha variado las dinámicas democráticas abriendo un nutrido campo de estudio sobre el papel de las cortes en la definición de las fronteras del constitucionalismo.

Adicionalmente, el ascenso del modelo concentrado de control constitucional de la ley también estuvo acompañado de una serie de renovaciones sobre la teoría jurídica. Desde la mitad del siglo XX las discusiones jurídicas se han ampliado, lo que ha generado un campo epistémico confuso y contradictorio. Se han convertido en una caja de herramientas desordenada que incluye instrumentos de calidad que muchas veces son utilizados para usos distintos a los que originalmente fueron pensados. La transmisión de la teoría jurídica y el constante flujo de información entre latitudes ha creado un proceso de bastardización en la forma como el conocimiento jurídico es apropiado, reproducido y aplicado. ${ }^{49} \mathrm{El}$ tráfico de información, a su vez, está transversalmente atravesado por una geopolítica del conocimiento jurídico - por utilizar los términos de Daniel Bonilla-, que amplifica el valor de las obras de auto-

$47 \quad$ Kurt Y. Bayer, “Hans Kelsen redactor de la Constitución Federal Austriaca, en especial de la Corte de Justicia Constitucional", en Revista de la Facultad de Derecho de México 55 (243) (2017), pp. 243-252, en http://www. revistas.unam.mx/index.php/rfdm/article/view/61392/54100

48 Idem.

49 Diego López-Medina, Teoría impura del Derecho: la transformación de la cultura jurídica en Latinoamérica, Bogotá, Legis, Universidad Nacional y Universidad de los Andes, 2004, pp. 61-71. 
res del norte global en espacios diferentes de sus contextos de creación. ${ }^{50}$ De esta forma, en escuelas del Sur Global se integran con regularidad las obras de teóricos como H.L.A. Hart, Ronald Dworkin y Robert Alexy como parte fundamental del canon educativo.

La imaginación jurídica latinoamericana ha empezado a asimilar productos jurídicos de otras latitudes con mayor rapidez ${ }^{51}$ y a responder a estas obras con un proceso continuo de calibración práctica y teórica. Esto también ha incentivado la creación de nuevas escuelas y nichos de producción de conocimiento que presentan con cada vez mayor eficacia innovaciones teóricas que responden al contexto regional. Conceptos como el neoconstitucionalismo, ${ }^{52}$ que han impactado en la región, han suscitado importantes discusiones sobre el papel de los tribunales constitucionales, sus prácticas interpretativas, la forma como adjudican derechos y sus relaciones con otras ramas del poder público. La discusión ha servido también como eje estructurante de una comunidad jurídica transnacional que ha consolidado "una concepción garantista de los derechos humanos y el Estado de derecho" ${ }^{53}$ que valora de forma positiva el "rol activo de los jueces y abogados en la promoción de la justicia social". ${ }^{54}$ Así, el paraguas teórico del neoconstitucionalismo, a pesar de sus múltiples discusiones internas, ha amparado y ayudado a soportar la confianza en el papel de los tribunales constitucionales en la región y en la forma como controlan los excesos de los poderes ejecutivos y legislativo, y al tiempo adjudican derechos.

Esto también ha servido para consolidar una cierta creencia de que los tribunales constitucionales balancean los tradicionalmente desbalanceados sistemas de frenos y contrapesos de la región, y que tal virtuoso posicionamiento favorece la consolidación de democracias robustas que permiten el diálogo y la deliberación pública. ${ }^{55}$ Lo que, a su vez, ha servido para soslayar sin realmente confrontar la llamada objeción democrática al poder judicial y al control constitucional de la ley. Es decir, la dificultad que estableció Alexander Bickel ${ }^{56}$ de formular un argumento que legitime los efectos contramayoritarios del con-

50 Daniel Bonilla-Maldonado, La geopolítica del conocimiento jurídico, Bogotá, Siglo del Hombre, Universidad de los Andes, 2015, p. 35.

51 Idem.

52 Término acuñado por la profesora italiana Susanna Pozzolo en el XVIII Congreso de la Asociación Mundial de Filosofía del Derecho y Filosofía Social, celebrado en Buenos Aires en 1997. Ahora bien, el término por sí mismo resulta complejo de delimitar. Para profundizar sobre el tema, varios autores han realizado importantes contribuciones para una definición de neoconstitucionalismo. A nivel internacional véase Paolo Comanducci, "Formas de (neo)constitucionalismo: un análisis metateórico", en Isonomía 16 (2002), pp. 89-112. En Colombia véase Leonardo García-Jaramillo, "El neoconstitucionalismo en Colombia: ¿entelequia innecesaria o novedad pertinente?", en Miguel Carbonell y Leonardo García-Jaramillo, eds., El Canon Neoconstitucional, Madrid, Trotta, 2010, pp. 311-365.

53 César Rodríguez Garavito, “Navegando la Globalización: un mapamundi para el estudio y la práctica del derecho en América Latina", en Rodríguez Garavito, coord., El derecho en América Latina. Un mapa para el pensamiento jurídico del siglo XXI, Buenos Aires, Siglo XXI, 2011, p. 16.

$180 \quad 54 \quad$ Ibid., p. 16.

55 Gargarella, R. La justicia frente al gobierno. Sobre el carácter contramayoritario del poder judicial, Quito, Corte Constitucional de Ecuador, 2011, p. 96.

56 Alexander Bickel, The Least Dangerorus Branch, New Heaven, Yale University Press, 1992, p. 16. 
trol constitucional de la ley -controversia que ha sido estudiada en diferentes latitudes por autores de la talla de Dworkin ${ }^{57}$ y Ferreres- ${ }^{58}$ Cuando afrontar esta discusión a través de las particularidades regionales constituye una tarea urgente y aún más retadora en aquellos espacios geográficos -como América Latina- que no han alcanzado un modelo de control recíproco y efectivo entre las ramas del poder público. ${ }^{59}$

Soslayar esta discusión y asumir la relación democrática del control judicial de la ley también ha ayudado a que la movilización legal se haya convertido en un instrumento importante y efectivo para el activismo político. Diversos movimientos han acudido a los estrados judiciales antes que a los órganos tradicionalmente políticos -como los parlamentos- para obtener respuesta ante sus demandas. Desde movimientos indígenas hasta la comunidad LGBTI han transformado sus reivindicaciones al lenguaje jurídico, afianzados por las redes neoconstitucionales, para alcanzar los estrados judiciales con eficacia. ${ }^{60}$ A pesar de que esto ha supuesto avances en adjudicación de derechos y ha permitido romper con temas vedados en los parlamentos latinoamericanos -como el aborto y el matrimonio homosexual-, también ha generado una confianza desproporcionada en los tribunales constitucionales. Tener confianza es suponer que algo o alguien va a actuar de determinada manera. Por ejemplo, que las cortes van a adoptar posiciones garantistas y progresivas frente a la adjudicación de derechos. O que las cortes van a poner freno a los posibles excesos de las ramas del poder público. Este tipo de confianza, que tiene que ver con el cumplimiento del rol institucional es proporcional. Sin embargo, tener confianza también alude a la esperanza de que algo va suceder sin mayor esfuerzo. Es decir, que la mera existencia de las cortes va a mantener los fundamentos democráticos y a expandir sus fronteras. Más aún, que el empuje de las Cortes puede considerarse por sí mismo favorable a la democracia. Este tipo de confianza resulta desproporcionada.

La duda, en este punto, supone un valioso aporte por parte de Gargarella. En la obra La justicia frente al gobierno -que adelantó con otro de los grandes maestros regionales: Carlos Santiago Nino- se articula una doble indagación que ofrece respuestas inversas sobre el control constitucional de la ley y el papel de las cortes. Por un lado, la obra cuestiona la necesidad del control constitucional de la ley para el mantenimiento de una democracia liberal. Para ofrecer una respuesta sobre esto, Gargarella presenta las razones que ofrecen

\footnotetext{
57 Cfr. Ronald Dworkin, Freedom's law, Cambridge, Harvard University Press, 1996.

58 Cfr. Víctor Ferreres Comella, "El control judicial de la constitucionalidad de la ley. El problema de su legitimidad democrática", en Miguel Carbonell y Leonardo García-Jaramillo, eds., El Canon Neoconstitucional, Madrid, Trotta, 2010, pp. 477-504.

59 Recientemente, en Colombia, se puede consultar la siguiente obra que ofrece justificación del control constitucional de la ley bajo un barniz democrático y deliberativo: Jorge Roa Roa, Control Constitucionalidad deliberativo. El ciudadano ante la justicia constitucional, la acción pública de constitucionalidad y la legitimidad democrática del control judicial al legislador, Bogotá, Universidad Externado de Colombia, 2019.

60 Véase Lemaitre Ripoll, El Derecho como conjuro, op. cit., 2009; Emilo Lehoucq Mazuera, “Constitución de 1991, Ley de Cuotas y movimiento feminista: el papel del derecho en la generación de estructuras de movilización", en Precedente (2016), p. 13.
} 
diferentes tradiciones ideológicas -como el conservadurismo ${ }^{61}$ y el radicalismo de corte republicano- ${ }^{62}$ para soportar un mecanismo de esta naturaleza. A partir de esta indagación extrae e individualiza las razones por las que el control constitucional de la ley deviene en una garantía para la autonomía individual. Con esta movida argumentativa, evidencia que es un mecanismo que permite corregir los posibles excesos del proceso legislativo que afectan el ámbito de soberanía moral de cada persona, al tiempo que puede maximizar la deliberación pública en la toma de decisiones, si está bien calibrado. ${ }^{63}$ De esta forma, Gargarella afirma la necesidad del control constitucional de la ley dentro de una democracia.

Por otro lado, después de afirmar la necesidad de este mecanismo la obra cuestiona su diseño. La duda se cierne sobre la adscripción del control constitucional de la ley al poder judicial. Mientras que la vanguardia neoconstitucional parte de la pacífica aceptación de naturaleza judicial de esta función, Gargarella muestra los orígenes conservadores de la rama judicial. Los jueces y las cortes de la región han sido utilizados con frecuencia por proyectos elitistas que cercenan una amplia participación democrática. En gran medida esto sucede porque las cortes son también susceptibles de ser cooptadas por proyectos políticos de inclinaciones autoritarias. En palabras de Gargarella:

Una última aclaración que, según creo, resulta válida para toda tarea de control: un órgano de revisión de las leyes cuya composición fuera como la actual, cuando menos seguiría siendo tan poco permeable como lo es hoy en día a las demandas de justicia de los grupos con menor poder de influencia dentro de la sociedad. Ello, a pesar de las buenas intenciones que puedan animar actualmente a algunos jueces. Por tanto, y como modo de remediar tales dificultades "epistémicas", he sugerido distintos medios capaces de vincular más estrechamente al órgano de control con las "voces" más vulnerables de la sociedad. ${ }^{64}$

La momentánea confianza en las cortes constitucionales está mediada porque el florecimiento del neoconstitucionalismo regional coincidió y se vio fortalecido por el papel de jueces comprometidos políticamente con estas tesis. ${ }^{65}$ Sin embargo, es desproporcionado que el buen funcionamiento de una democracia y la ampliación de las discusiones públicas descanse en el compromiso político de los jueces. Pues, si este llegase a extinguirse -como ya está sucediendo en cortes etiquetadas como activistas-, las demandas de justicia de los sectores históricamente marginados se verían de nuevo bloqueadas. Es ahí donde subyace la desproporción, pues la posibilidad de que la demanda de justicia sea relevante y reciba alguna respuesta por parte del Estado no debe depender

63 Es decir, si tiene definidas sus competencias. Gargarella considera que las cortes no deben interferir excesivamente en los debates parlamentarios. Para evitar esto, es necesario calibrar su ámbito de competencia para que sirvan como potenciador y no como un obstructor del debate público.

64 Gargarella, La justicia frente al gobierno, op. cit., p. 281.

65 Rodríguez Garavito, "Navegando la Globalización, op. cit., p. 16. 
del compromiso político de un juez o una corte. Menos aun cuando los jueces adolecen de representación democrática en sentido estricto -a pesar de que se pueda argumentar que ejercen una representación argumentativa como lo propone Roa Roa- ${ }^{66} \mathrm{~A}$ su vez, esto le permite a Gargarella consolidar su crítica en el campo propositivo. Si los jueces son permeables y no son un filtro lo suficientemente confiable, es necesario rediseñar el mecanismo de control constitucional de la ley de tal forma que estos participen y consigan los propósitos valiosos de este, pero sin que tengan la última palabra para bloquear una demanda de justicia. En este sentido, Gargarella niega que sean los jueces quienes deban tener la última palabra en asuntos constitucionales. Este cuestionamiento, entonces, se convierte en un llamado a la imaginación jurídica de la región para que imprima creatividad frente a este problema.

Gargarella enuncia el problema, hace el llamado, pero también da los primeros pasos para buscar una solución. Su declaración es simple pero contundente: hay que empezar a conectar a la población -a la ciudadanía- para que se vincule al mecanismo de control constitucional de la Ley. La experiencia colombiana a través de la acción pública de inconstitucionalidad resulta valiosa pues cualquier ciudadano puede acceder a la justicia constitucional a través de esta. Sin embargo, el sistema de filtros que ha diseñado la Corte Constitucional colombiana con el objetivo de evaluar la aptitud de la acción para activar el control de la ley ha elitizado la figura y ha mermado una parte de su potencial democrático ${ }^{67}$ Otras propuestas, como la de Joel Colon Ríos, también entienden el déficit democrático del control constitucional de la ley y buscan mecanismos que permitan vincular a la población. La idea de un poder constituyente débil cuya activación no renueva toda la institucionalidad, sino que dialoga con esta para definir las controversias constitucionales supone un avance hacia modelos democráticos menos elitistas y más deliberativos. ${ }^{68}$

Al final, la preocupación de Gargarella es simple: las cortes pueden servir al autoritarismo. Por ende, llevar el constitucionalismo más allá de las cortes acercándolo a la ciudadanía constituye una garantía robusta, pues supone una devolución del poder constitucional a quien lo origina. El camino, en consecuencia, es rediseñar mecanismos como el control constitucional de ley acercándolo a la gente. Esto responde a que el constitucionalismo no es monopolio de la cortes, sino una garantía de la ciudadanía y el mejor antídoto ante un proyecto autoritario es que la población tenga poder en las decisiones constitucionales.

66 Cfr. Roa Roa, Control Constitucionalidad deliberativo, op. cit., pp. 242-259.

67 El sistema de filtros consiste en que cada acción pública de inconstitucional supere los siguientes requisitos de claridad, certeza, especificidad, pertinencia y suficiencia como parte de un examen preliminar que realiza la Corte sobre la demanda de constitucionalidad. Para profundizar véase Roa Roa, Control de Constitucionalidad deliberativo, op. cit., p. 97.

68 Joel Colon Ríos, Weak Constitucionnalism. Democratic Legitimacy and the Question of Constituent Power, London, Routlege, 2012, p. 10; La Constitución de la Democracia, Bogotá, Universidad Externado de Colombia, 2013, p. 73. 


\subsection{Redefinir el papel de la ciudadanía}

El constitucionalismo siempre ha utilizado ficciones para adquirir potencia. Conceptos como soberanía, poder constituyente y pueblo constituyen una gramática evocativa que genera imágenes sugestivas sobre el talante del acto constitucional. El concepto de pueblo es tal vez el que con mayor intensidad ha cautivado la imaginación política. No es en vano que la Constitución de Filadelfia de 1776 inicie con la expresión We, The People; que el preámbulo de la Constitución francesa de 1793 inicia con Le peuple français; y que la Constitución de la Gran Colombia de 1821, después de invocar el poder de Dios, prosiga con la expresión los representantes de los pueblos de Colombia. El pueblo está presente, así sea simbólicamente, en el acto constitucional; tanto que es difícil encontrar una constitución que no lo invoque como uno de sus referentes de legitimidad.

La idea de pueblo contrasta con otra de las categorías centrales del lenguaje jurídico, el ciudadano. La narrativa constitucional tiene cierta linealidad entre ambas ideas: el pueblo, al momento de establecer una constitución, también configura un conjunto de derechos y deberes para quienes se acogen a ese régimen, que a su vez llenan de contenido la noción de ciudanía. En este sentido, el pueblo utiliza el acto constitucional para establecer el conjunto de garantías que tiene cada persona frente al ejercicio del poder del Estado, así como los deberes con sus conciudadanos. La articulación entre derechos y deberes balancea el ejercicio ciudadano e idealmente fortalece la democracia. De esta forma, quien puede ejercer su derecho a participar políticamente, está más presto a cumplir de manera voluntaria con las decisiones que toman las autoridades públicas. En cambio, quien se siente excluido de la participación política, es propenso a rechazar la forma como actúan las autoridades. La ciudadanía se vuelve así el eje sobre el que se articula la legitimidad del sistema político. A su vez, esto implica que el carácter ficcional y evocativo del pueblo adquiere forma a través del molde de la ciudadanía.

En América Latina, la ciudadanía está desbalanceada: el ejercicio de derechos es restringido, pero se mantiene la exigencia de los deberes. Bajo este esquema, las cualidades cívicas son precarias. No porque las personas que integran las sociedades de la región carezcan de las capacidades para desarrollarlas, sino porque el mismo desbalance en la ciudadanía desaconseja su desarrollo. Por ejemplo, pagar impuestos en sociedades bien organizadas -por utilizar los términos de Rawls- es percibido como un deber ciudadano frente al bien común. En cambio, el mismo acto en sociedades menos organizadas supone un desagradable sacrificio que en lo posible se debe evitar. En consecuencia, la dificultad de consolidar una empresa común supone también una dificultad aún más intensa para justificar los deberes de cada persona frente a esta empresa. Así, si son restringidos derechos básicos como la protesta; deberes básicos como la solidaridad entre los ciudadanos resultan risibles. 
El desbalance en la ciudadanía contribuye a distanciar al pueblo de las instituciones democráticas. Gargarella utiliza la expresión de disonancia democrática para explicar el contraste entre el poder evocativo del pueblo en el acto constitucional y el desbalance en el ejercicio de la ciudadanía. ${ }^{69} \mathrm{Su}$ argumento consiste en evidenciar que el constitucionalismo regional fortalece tradicionalmente un proyecto político elitista que cercena la posibilidad de una amplia participación democrática, pero encubre este proyecto a través de la narrativa de empoderamiento popular a través de la figura del pueblo empoderado. El carácter ficcional del pueblo se utiliza para que adquiera potencia un régimen político de corte elitista. Las deficiencias en el ejercicio de la ciudadanía, en consecuencia, demuestran el uso de esta narrativa y suponen la existencia de la disonancia. Las personas tienen expectativas de que su opinión cuenta, pero no encuentran mecanismos para expresarla, por lo que se sienten defraudadas. La única vía en la región suelen ser las elecciones periódicas a las ramas representativas del poder público, principalmente a la presidencia y a los parlamentos. Sin embargo, las opciones en estas contiendas democráticas son escasas y muchas veces las diferencias entre las posturas políticas resultan superfluas ante sus similitudes. Así, "buena parte de los 'puentes' de comunicación existentes, imaginados o posibles entre ciudadanos y representantes han sido 'dinamitados'"'. ${ }^{70}$ Esto ha impulsado un descontento popular frente al sistema político existente, incluso cuando tiene rasgos medianamente democráticos.

Desde la visión de Gargarella, la disonancia democrática tiene su origen en el diseño y la distribución del poder público, en la medida que hace imposible el robusto ejercicio de la ciudadanía. Sin embargo, la solución de estos problemas, es decir, la mejor distribución del poder público, no implica la solución de la disonancia democrática. Son dos dimensiones distintas que, a pesar de que están interconectadas, precisan de soluciones diferentes. Esta lección es fundamental. En sus palabras:

Imagine that we put an end to the extended practice of Executive's abuses; that we finally limit the dismantling of all the existing controlling devices, etc. Now, even if we magically achieved those ambitious goals, a central part of our "democracyerosion"-problem would still be in its place, fundamentally untouched. For one thing, people would continue to feel alienated from power and disengaged from democracy. And this would be so because the problems posed by the crisis of constitutionalism significantly differ from those posed by the crisis of democracy. In other words, people do not feel politically alienated because, say, judges are not checking

69 Roberto Gargarella, "Review of Tom Ginzburg and Aziz Huq, 'How to Save a Constitutional Democracy'”, en Revista Derecho del Estado (44) (2019), pp. 397-406. DOI: https://doi.org/10.18601/01229893.n44.15.

70 Roberto Gargarella, "Pensar la Democracia. Discutir sobre los derechos", en Nueva Sociedad (267) (2017), pp. $102-113$. 
the Executive; legislators are too deferent towards the President; or the Executive is not properly controlled. "We the People" feel distanced from politics because they have still very few chances to meaningfully participate in politics. ${ }^{71}$

Solucionar los problemas constitucionales es necesario para desmantelar los proyectos elitistas de la región. Sin embargo, no es suficiente para remediar la disonancia democrática. Esta última precisa más que arreglos institucionales. El punto de partida es asumir que la política no se reduce a las elecciones, y que las instituciones políticas, aun cuando tienen un talante democrático, son capaces de absorber todas las manifestaciones políticas por parte de la ciudadanía. Por el contrario, la institucionalidad es una porción de lo político. El resto descansa en la ciudadanía que es quien debe definir las formas como se manifiesta. La libertad de reunión, de expresión y la protesta pública, en consecuencia, no solo son esenciales dentro de un sistema democrático, sino que suponen un espacio de desarrollo ciudadano y de lo político independiente de la institucionalidad. De esta forma, debe empezarse a consolidar un imperativo moral en la región que permita favorecer este tipo de expresiones. Aún más, cuando disienten y critican el actuar de los mecanismos institucionales de toma de decisiones públicas. Este es el paso necesario para empezar a redefinir la ciudadanía en la región, a fin de que esta salga del estrecho salón en que tradicionalmente se la ha confinado: el de la representación política.

La protesta, por ejemplo, no solo es un medio para que la ciudadanía se exprese ante su descontento con el poder institucional. También es un canal de diálogo entre la misma ciudadanía que permite consolidar espacios de discusión. Lo mismo pasa con la libertad de expresión y de reunión. El déficit histórico de la región en términos de participación política no se remedia únicamente en razón de la ampliación del espectro de representación política, ni del adecuado equilibrio entre los poderes institucionales, sino que está atado de forma indisoluble a la redefinición de la ciudadanía y la necesidad de que este soslaye la imposición de la representación política como único canal de expresión. Tal vez de esta forma se pueda superar la imagen de los votos como "golpes

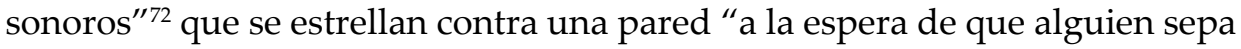
reconocer o leer el 'mensaje' que encerramos en ellos". ${ }^{73}$ Ya que el golpe en la pared va a estar acompañado de la bulla en la calle.

\section{Conclusión}

En Pedro Páramo, el escritor mexicano Juan Rulfo esboza una imagen de Comala, un pueblo ficticio en el que se desarrollan la narración. El protagonista 
de la novela, Juan Preciado, va en busca de su padre -quien le da nombre a la obra- con el objetivo de cobrarle su abandono. La madre de Juan le describe a Comala como un pueblo verde, lleno de vida; sin embargo, cuando Juan llega allí el pueblo está abandonado. Las personas con las que Juan se encuentra en Comala son reflejos e ilusiones, por lo que él termina deambulando entre fantasmas sin poder distinguir lo vivo de lo muerto. La experiencia constitucional latinoamericana tiene un parecido con la experiencia de Juan Preciando al llegar a Comala. Las naciones de la región utilizaron una narrativa constitucional que encarna una promesa: el gobierno autónomo y popular. Equiparable a lo verde y lo vivo. Pero descubrieron que tuvo un efecto contrario, proyectos políticos elitistas y con rasgos autoritarios, equiparables a un pueblo vacío, cuyos habitantes son solo reflejos y fantasmas. La sensación de no poder distinguir entre lo que está vivo y lo que está muerto, que desconcierta a Juan, es la misma sensación de muchos pueblos que se dieron cuenta de que solo eran ficciones en los textos constitucionales. Constituciones vacías de los aspectos esenciales del constitucionalismo. $\mathrm{O}$, en otras palabras, enmascaramientos del autoritarismo.

El aporte de Roberto Gargarella al constitucionalismo de la región consiste en una relectura crítica que permite evidenciar el carácter contramayoritario del constitucionalismo latinoamericano. Sin embargo, su contribución no es únicamente la descripción de los síntomas, sino que avanza en una propuesta para resistir a las nuevas formas que adopta el autoritarismo y que, en alguna medida, ponen en crisis algunos de los seguros del constitucionalismo. Esta receta, si bien aún está en construcción, tiene tres elementos bien formados que se extraen de la reconstrucción de las obras de Gargarrela: i) poner la lupa en la distribución del poder público, incluso antes de las consagraciones de las cartas de derechos; ii) repensar en clave popular los mecanismos de control de constitucionalidad para desmontar la confianza en que las constituciones, y el constitucionalismo, sean defendidos principalmente por las cortes; y iii) construir nuevos espacios de lo político que excedan lo electoral, para que los ciudadanos encuentren formas significativas y democráticas de participación. Estos elementos nos ayudan a evitar la experiencia de Juan cuando llegó a Comala, es decir, a no distinguir lo vivo de lo muerto, el constitucionalismo del autoritarismo.

\section{Agradecimientos}

Quiero agradecer a Juliana Nariño, quien me animó a emprender la escritura de este artículo aun cuando el tiempo estaba en mi contra. Ella nunca me abandonó en esta desenfrenada travesía y estuvo pendiente de cada letra que está en el texto. Las virtudes que pueda llegar a tener se las debo a ella; los errores son solo míos. 


\section{Bibliografía}

Albright, M., Fascisim: A warning, New York, Harper Collins, 2018.

Ávila, Ariel, Detrás de la Guerra en Colombia, Bogotá, Planeta Editores, 2019.

Bayer, Kurt Y., "Hans Kelsen redactor de la Constitución Federal Austriaca, en especial de la Corte de Justicia Constitucional", en Revista de la Facultad de Derecho de México 55 (243), pp. 243-252. DOI: https://doi.org/10.22201/ fder.24488933e.2005.243.61392

Benítez, Vicente F., Constitución Popular, No judicial, Bogotá, Universidad de la Sabana, 2014.

Bickel, Alexander, The Least Dangerous Branch, New Heaven, Yale University Press, 1992.

Bonilla-Maldonado, Daniel, La geopolítica del conocimiento jurídico, Bogotá, Siglo del Hombre, Universidad de los Andes, 2015. DOI: https://doi.org/10.4000/ books.sdh. 621

Colon Ríos, Joel, La Constitución de la Democracia, Bogotá, Universidad Externado de Colombia, 2013.

Colon Ríos, Joel, Weak Constitucionnalism. Democratic Democratic Legitimacy and the Question of Constituent Power, London, Routlege, 2012.

Comanducci, Paolo, "Formas de (neo)constitucionalismo: un análisis metateórico", en Isonomía 16 (2002), pp. 89-112.

Dworkin, R., Freedom's law, Cambridge, Harvard University Press, 1996.

Eslava, L., "El estado desarrollista: independencia, dependencia y la historia del Sur", en Revista Derecho del Estado 43 (2019), pp. 25-65. DOI: https://doi. org/10.18601/01229893.n43.03

Ferreres Comella, V., “El control judicial de la constitucionalidad de la ley. El problema de su legitimidad democrática", en Miguel Carbonell y Leonardo García-Jaramillo, eds., El Canon Neoconstitucional, Madrid, Trotta, 2010, pp. 477-504.

Frankenberg, Günter, "Authoritarian constitutionalism: Coming to terms with modernity nightmares", en Günter Frankenberg y Helena Alvear, eds., Authoritarian Constitutionalism, Cheltenhan UK, Eward Elgar, 2019, pp. 1-37. DOI: https://doi.org/10.4337/9781788117852.00006

Fukuyama, Francis, The end of history and the last man, New York, The Fress Press. 
García-Jaramillo, Leonardo, "El neoconstotucionalismo en Colombia: ¿entelequia innecesaria o novedad pertinente?", en Miguel Carbonell y Leonardo García-Jaramillo, eds., El Canon Neoconstitucional, Madrid, Trotta, 2010, pp. 311-365.

García-Villegas, Mauricio, “Constitucionalismo aspiracional: derecho, democracia y cambio social en América latina", en Análisis Político (75) (2012), pp. 89-110.

Gargarella, Roberto, ¿Qué es la Constitución?, en http://lalibertaddepluma. org/roberto-gargarella/, fecha de consulta: 10 de mayo de 2020.

Gargarella, Roberto, "Pensar la Democracia. Discutir sobre los derechos", en Nueva Sociedad (267) (2017), pp. 102-113.

Gargarella, Roberto, "Review of Tom Ginzburg and Aziz Huq, 'How to Save a Constitutional Democracy"', en Revista Derecho del Estado (44) (2019), pp. 397-406. DOI: https://doi.org/10.18601/01229893.n44.15

Gargarella, Roberto, Castigar al prójimo: por una refundación democrática del derecho penal, Buenos Aires, Siglo Veintiuno Editores, 2016.

Gargarella, Roberto, La justicia frente al gobierno. Sobre el carácter contramayoritario del poder judicial, Quito, Corte Constitucional de Ecuador, 2011.

Gargarella, Roberto, La sala de máquinas de la constitución. Dos siglos de constitucionalismo en América Latina (1810-2010), Buenos Aires, Katz Editores, 2014. DOI: https://doi.org/10.2307/j.ctvm7bcjw

Gargarella, Roberto, Los fundamentos legales de la desigualdad. El constitucionalismo en América (1776- 1860), Buenos Aires, Siglo XX, 2005.

Ginsburg, T. y A. Simpser, Constitutions in Athoritariam Regimes, Cambridge, Cambridge University Press, 2014. DOI: https://doi.org/10.2139/ ssrn. 2427794

Ginsburg, T. y Aziz Z. Huq, How to save a constitutional democracy, Chicago, University of Chicago Press, 2018. DOI: https://doi.org/10.2307/j.ctvm7bcjw

Glasious, Marlies, "What authoriarianism is... and is not: A practical perspective", en International Affairs 94 (3) (2018), pp. 515-533. DOI: https://doi. org/10.1093/ia/iiy060

González Jácome, Jorge, "Authoritarianism and the narrative power of constitutionalism in Venezuela", en Günter Frankenberg y Helena Alvear, eds., Authoritarian Constitutionalism, Cheltenhan UK, Eward Elgar, 2019, pp. 136-160. DOI: https://doi.org/10.4337/9781788117852.00012 
González Jácome, Jorge, "From abusive constitutionalism to a multilayered understanding of constitutionalism: Lessons from Latin America", en I•CON 15 (2) (2017), pp. 447-468. DOI: https://doi.org/10.1093/icon/mox017

Habermas, Jürgen, Identidades nacionales y postnacionales, Madrid, Tecnos, 1989.

Hobsbawm, Erik, The age of revolution 1789-1848. New York, Vintage Books, 1996.

Iturralde, Manuel y Libardo Ariza, Los muros de la infamia. Prisiones en Colombia y en América Latina, Bogotá, Ediciones Uniandes, 2011.

Kennedy, Duncan, "Authoritarian constitutionalism in liberal democracies", en Günter Frankenberg y Helena Alvear, eds., Authoitarian constitucionalism, Cheltenhan UK, Eward Elgar, 2019, pp. 161-185. DOI: https://doi. org/10.4337/9781788117852.00013

Landau, D. “Abusive Constitutionalism", en 47 UC Davis Law Review 189 (2013).

Law, David S. y Mila Versteeg, Constitucionales aparentes y variaciones constitucionales entre corrientes de autoritarismo, Bogotá, Universidad Externado de Colombia, 2018.

Lehoucq Mazuera, Emilio, “Constitución de 1991, Ley de Cuotas y movimiento feminista: el papel del derecho en la generación de estructuras de movilización", en Precedente (2016), pp. 13-4.

Lemaitre Ripoll, Julieta, El derecho como conjuro: fetichismo legal, violencia y movimientos sociales, Bogotá D.C., Siglo del Hombre Editores, Universidad de los Andes, 2009.

Lerner, Hanna, Making Constitutions in Deeply Divided Societies, New York, Cambridge University Press, 2011.

Levisky, Steven y Daniel Ziblatt. How Democracies Die, New York, Crown, 2018.

Loewenstein, Karl, "La 'Presidencia' por fuera de los Estados Unidos", en Boletín del Instituto de Derecho Comparado de México II (5) (1949), pp. 16-64.

López-Medina, Diego, “El nacimiento del derecho comparado moderno como espacio geográfico y como disciplina: instrucciones básicas para su comprensión y uso desde América Latina", International Law, Revista Colombiana de Derecho Internacional 26 (2015), pp. 117-159. http://dx.doi.org/10.11144/ Javeriana.il15-26.ndcm

López-Medina, Diego, Teoría impura del Derecho: la transformación de la cultura jurídica en Latinoamérica, Bogotá, Legis, Universidad Nacional y Universidad de los Andes, 2004. 
Madison, J., "Federalist No. 10", en A. Hamilton, J. Madison, y J. Jay, The Federalist Papers, New York, Palgrave Macmillan, 2009, pp. 49-55. DOI: https:// doi.org/10.1057/9780230102019_6

Mounk, Yascha, The people vs. Democracy. Why our freedom is in danger and how to save it, London, Harvard University Press, 2018. DOI: https://doi. org/10.4159/9780674984776

Nussbaum, Martha, Policial Emotions: Why love matters to justice, Cambridge MA, Harvard University Press, 2013.

Roa Roa, Jorge, Control de constitucionalidad deliberativo. El ciudadano ante la justicia constitucional, la acción pública de constitucionalidad y la legitimidad democrática del control judicial al legislador, Bogotá, Universidad Externado de Colombia, 2019. DOI: https://doi.org/10.2307/j.ctv1k03p22

Rodríguez Garavito, César, “Navegando la Globalización: un mapamundi para el estudio y la práctica del derecho en América Latina", en Rodríguez Garavito, coord., El derecho en América Latina. Un mapa para el pensamiento jurídico del siglo XXI, Buenos Aires, Siglo XXI, 2011.

Salazar Urguarte, Pedro, "El Nuevo Constitucionalismo Latinoamericano (una perspectiva crítica)", en Política y Derecho: derechos y garantías, México D.F., Marcial Pons, 2013.

Serrano-Mancilla, Alfredo, “¿Por qué es fundamental estudiar la Constitución Económica de Ecuador?" en Serrano-Mancilla, coord., La Nueva Economía en la nueva Constitución de Ecuador, Providence, Brown University, 2015, pp. 13-16. 